\title{
THE IMMUNOLOGIC IDENTIFICATION AND QUANTITATION OF HUMAN INTRINSIC FACTOR IN GASTRIC SECRETIONS *
}

\author{
By GRAHAM H. JEFFRIES and MARVIN H. SLEISENGER with THE TEChNICAL \\ ASSISTANCE OF LLOYD L. BENJAMIN
}

(From the Department of Medicine, The New York Hospital-Cornell Medical Center, New York, N.Y.)

(Submitted for publication August 3, 1962; accepted December 6, 1962)

Intrinsic factor (IF) differs from other naturally occurring, vitamin $\mathrm{B}_{12}$-binding substances in its ability to promote the intestinal absorption of vitamin $B_{12}$. Thus, in patients with pernicious anemia, a failure of IF secretion causes vitamin $\mathrm{B}_{12}$ malabsorption, although other vitamin $\mathrm{B}_{12^{-}}$ binding substances are present in both their saliva and gastric juice (1-4). The presence of IF in gastric secretions or gastric mucosal preparations can be established only on the basis of this biological property, the ability to promote vitamin $\mathrm{B}_{12}$ absorption.

An antibody that combines with and inactivates human IF has been identified in the sera of some patients with pernicious anemia (5-7). If this antibody could be shown to combine specifically with human IF, a sensitive in vitro method to identify and to measure IF could be developed. Such an in vitro test would have both clinical application and usefulness as an investigative tool in studies on IF.

The experiments herein described were carried out to define the specificity of this interaction between naturally occurring IF antibody and human IF. Vitamin $\mathrm{B}_{12}$-binding substances saturated with cobalt ${ }^{60}$-labeled vitamin $\mathrm{B}_{12}\left(\mathrm{Co}^{60} \mathrm{~B}_{12}\right)$ were separated by electrophoresis of saliva and gastric secretions and were tested for their ability to combine with antihuman IF $\gamma$-globulin from pernicious anemia serum (7). A bound $\mathrm{Co}^{60} \mathrm{~B}_{12}$ complex that combined with antihuman IF $\gamma$-globulin was present only in acid gastric juices or in the achlorhydric gastric juice from patients with normal vitamin $\mathrm{B}_{12}$ absorption. $\mathrm{Co}^{60} \mathrm{~B}_{12}$-binding fractions from gastric juice of patients with pernicious anemia or from saliva did not react. On the basis of this specific immunological reaction

* This investigation was supported in part by U. S. Public Health Service research grant CS 9386 from the National Cancer Institute, Bethesda, Md. between antihuman IF $\gamma$-globulin and IF, an in vitro test for human IF is suggested.

\section{METHODS}

Patients and gastric juice collection. Studies were carried out on gastric secretions and saliva from patients with pernicious anemia, with atrophic gastritis but without pernicious anemia, and with normal gastric secretion of acid. The diagnosis of pernicious anemia had been established by demonstration of $a$ ) a macrocytic anemia with megaloblastic bone marrow, $b$ ) gastric achlorhydria on maximal histamine stimulation (8), and c) subnormal absorption of vitamin $B_{12}$ which was corrected by IF. Patients with atrophic gastritis without pernicious anemia exhibited achlorhydria on maximal histamine stimulation and atrophy of the fundal gastric mucosa with absent parietal and chief cells on gastric biopsy. Vitamin $\mathrm{B}_{12}$ absorption measured by a modified Schilling test (9) was either normal or slightly decreased in these patients, and vitamin $B_{12}$ deficiency as evidenced by megaloblastic anemia was not present.

Gastric secretion was stimulated in fasting subjects by a subcutaneous injection of histamine phosphate $(0.04$ $\mathrm{mg}$ per $\mathrm{kg}$ ) given 20 minutes after intramuscular chlorprophenpyridamine maleate $(20 \mathrm{mg})$. The fasting contents of the stomach were discarded, as were secretions contaminated by blood or bile. Gastric juice collected during 30 minutes, beginning 15 minutes after histamine injection, was used in this study. Secretions were immediately chilled to $4^{\circ} \mathrm{C}$, and surface mucus and epithelial debris were removed by centrifugation at $2,500 \mathrm{~g}$ for 10 minutes. The $\mathrm{pH}$ of the gastric juice was measured electrometrically, and acid secretions were neutralized by adding $0.3 \mathrm{M}$ borate buffer at $\mathrm{pH} 8.6$ to prevent further peptic digestion of vitamin $\mathrm{B}_{\mathbf{1 2}}$-binding components. Electrophorctic separation and quantitation of $\mathrm{Co}^{80} B_{12-}$ binding substances from saliva and gastric juice. $\mathrm{Co}^{\infty 0} \mathrm{~B}_{12}{ }^{1}$ (specific activity, $1 \mu \mathrm{c}$ per $\mu \mathrm{g}$ of vitamin $\mathrm{B}_{12}$ ) was added to $0.2-\mathrm{ml}$ volumes of saliva or gastric juice (achlorhydric or neutralized) within 30 minutes of their collection. The concentration of added vitamin $B_{12}$ in saliva or gastric juice from patients with pernicious anemia varied between 240 and $560 \mathrm{~m} \mu \mathrm{g}$ per $\mathrm{ml}$ of secretion. In neutralized gastric juice and the achlorhydric gastric juice from patients with normal vitamin $B_{12}$ absorption, the concentration

\footnotetext{
1 Obtained from Abbott Laboratories, Oak Ridge, Tenn.
} 
varied between 480 and $560 \mathrm{~m} \mu \mathrm{g}$ vitamin $\mathrm{B}_{12}$ per $\mathrm{ml}$ of undiluted secretion. Each mixture was introduced into a transverse slot in a starch gel electrophoretic strip, and electrophoresis was carried out at $10^{\circ} \mathrm{C}$ for 5 hours at a constant voltage of $6 \mathrm{v}$ per $\mathrm{cm}$ and at $\mathrm{pH} 8.6$ (10). The distribution of radioactivity was measured by counting $1-\mathrm{cm}$ segments of the electrophoretic strip in plastic tubes in a well-type scintillation counter.

Anodally migrating, bound $\mathrm{Co}^{60} \mathrm{~B}_{12}$ in saliva or gastric juice was separated from the cathodally migrating, unbound (free) $\mathrm{Co}^{80} \mathrm{~B}_{12}(10)$. The content of vitamin $\mathrm{B}_{12}{ }^{-}$ binding substances in each secretion, expressed as $\mathrm{m} \mu \mathrm{g}$ of vitamin $B_{12}$ bound by $1 \mathrm{ml}$ of secretion, was calculated from the equation: vitamin $B_{12}$-binding capacity ( $m \mu g$ per $m l)=[$ anodally migrating radioactivity $(\mathrm{cpm}) /$ total radioactivity recovered on the electrophoretic strip ( $c p m)$ ] $\times$ concentration of vitamin $B_{12}$ added to the secretion ( $m \mu g B_{12}$ per $m l$ of undiluted secretion). The possibility that radioactive breakdown products of $\mathrm{Co}^{60} \mathrm{~B}_{12}$ migrated anodally and contaminated the bound $\mathrm{Co}^{80} \mathrm{~B}_{12}$ fractions was excluded by starch gel electrophoresis of $\mathrm{Co}^{60} \mathrm{~B}_{12}$ alone. Radioactivity was confined to cathodal segments.

Interaction of $\mathrm{Co}^{\mathrm{o0}} B_{12}$-binding fractions from gastric juices and saliz'a with antihuman IF r-globulin. Gamma globulin was prepared by starch gel electrophoresis of sera from normal subjects and from a patient with pernicious anemia. The latter serum had been shown to
TABLE I

The concentration of added $\mathrm{Co}^{60} B_{12}$ bound to intrinsic factor in normal, neutralized gastric juices

\begin{tabular}{|c|c|c|c|c|c|}
\hline \multirow[t]{3}{*}{$\begin{array}{l}\text { Sample } \\
\text { no. }\end{array}$} & \multirow{3}{*}{$\begin{array}{c}\begin{array}{c}\text { Total } \\
\text { B } \\
\text { capacity }\end{array} \\
\begin{array}{c}m \mu g B_{12} / m l \\
\text { gastric juice }\end{array}\end{array}$} & \multicolumn{2}{|c|}{$\begin{array}{l}\text { Percentage of } \\
\text { bound } \mathrm{B}_{12} \\
\text { combining with } \\
\text { antibody }\end{array}$} & \multicolumn{2}{|c|}{$\begin{array}{l}\text { IF-C } \mathrm{Co}^{60} \mathrm{~B}_{12} \text { content } \\
\text { of secretion }\end{array}$} \\
\hline & & \multicolumn{2}{|c|}{$\%$} & \multicolumn{2}{|c|}{$\underset{\text { gastric juice }}{m \mu g \text { bound }} B_{12} / m l$} \\
\hline & & $A$ & $B$ & $A$ & B \\
\hline 1 & 290 & 14.4 & 15.7 & 41.7 & 45.5 \\
\hline 2 & 134 & 34.8 & 36.2 & 46.6 & 48.5 \\
\hline 3 & 130 & 37.3 & 39.0 & 48.8 & 50.3 \\
\hline 4 & 109 & 33.5 & 33.7 & 36.5 & 36.7 \\
\hline 5 & 228 & 75.6 & 73.0 & 172.0 & 166.4 \\
\hline 6 & 163 & 40.5 & 44.0 & 66.0 & 71.8 \\
\hline 7 & 123 & 26.8 & 25.5 & 33.0 & 31.0 \\
\hline 8 & 113 & 47.5 & 47.9 & 53.6 & 54.2 \\
\hline 9 & 154 & 64.1 & 59.0 & 99.0 & 91.0 \\
\hline 10 & 243 & 49.1 & 48.8 & 115.0 & 114.3 \\
\hline 11 & 105 & 26.8 & 27.7 & 28.3 & 29.3 \\
\hline
\end{tabular}

contain $\gamma$-globulin which combined with and inactivated a partially purified preparation of $\mathrm{Co}^{60} \mathrm{~B}_{12}$-labeled human IF. The $\gamma$-globulin in $1 \mathrm{ml}$ of this serum combined with $58 \mathrm{~m} \mu \mathrm{g}$ of $\mathrm{Co}^{60} \mathrm{~B}_{12}$ bound to IF [ (7), Table I, Patient 1]. Electrophoresis of $0.4-\mathrm{ml}$ volumes of sera was carried out for 5 hours at $\mathrm{pH} 8.6$ and a constant voltage of $6 \mathrm{v}$

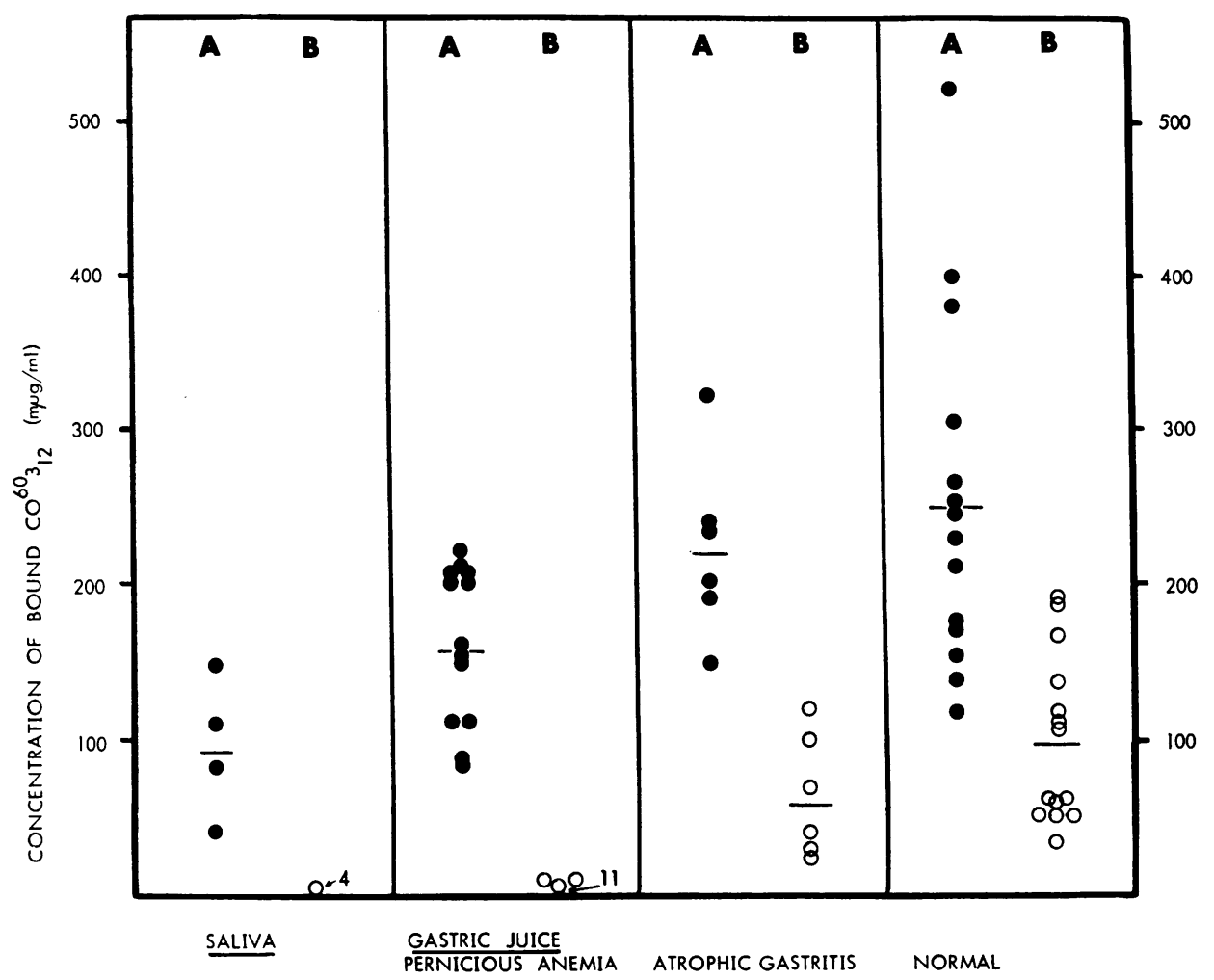

Fig. 1. The concentration of vitamin $B_{12}$-binding substances in saliva and gastric SECRETIONs. A. Total concentration of bound $\mathrm{Co}^{60} \mathrm{~B}_{12}$. B. Quantity of IF-bound $\mathrm{B}_{12}$ as estimated by antibody technique. 
TABLE II

The concentration of vitamin $B_{12}$-binding substances in gastric juices and saliva

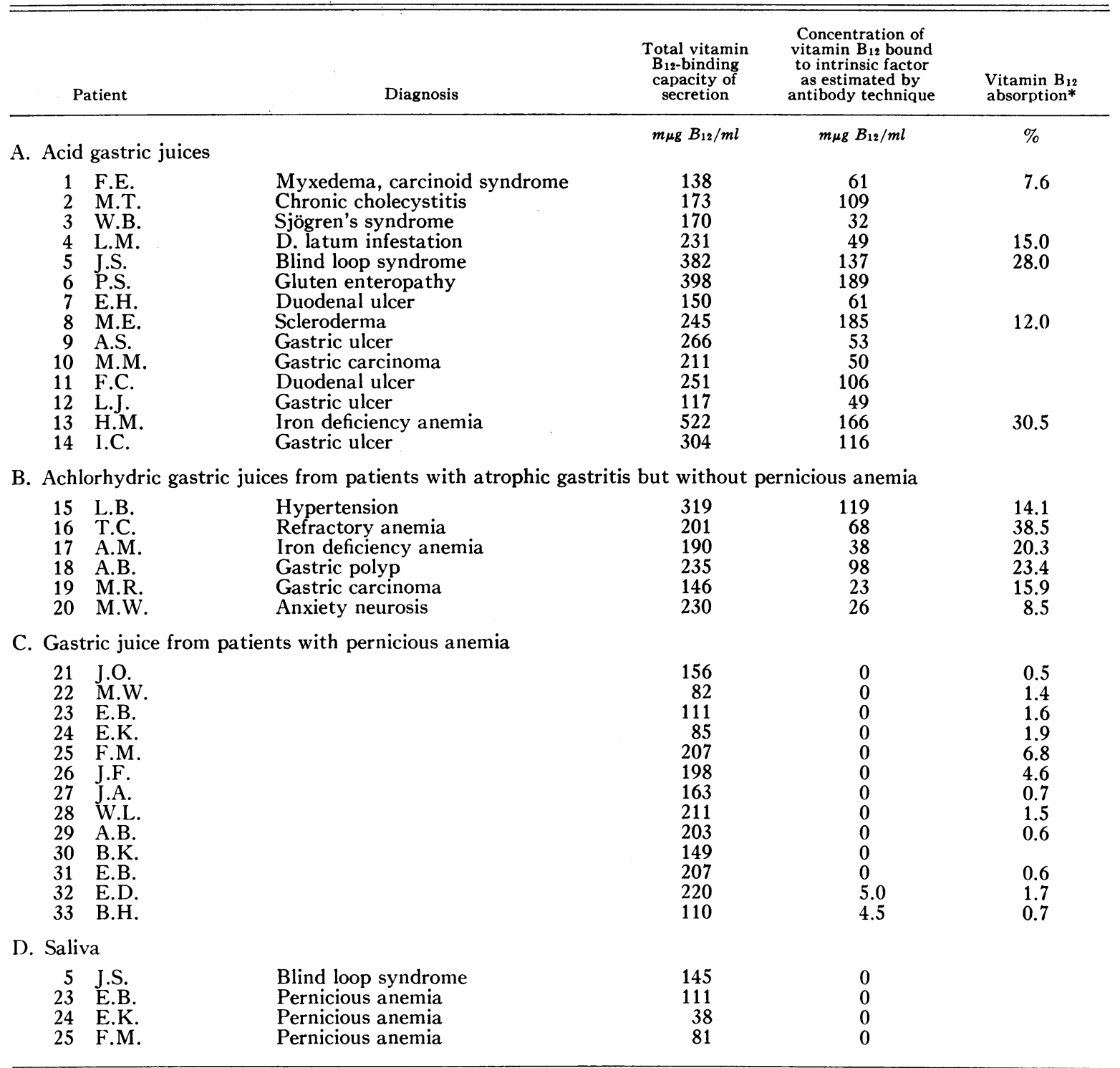

* 48-hour urinary excretion of an oral dose of $0.2 \mu \mathrm{g}$ of $\mathrm{Co}^{60} \mathrm{~B}_{12}$. Normal value, the mean of 15 subjects, is $24.0 \%$; range, 12.1 to $30.5 \%$; $\mathrm{SD}, 6.44 \%$.

per $\mathrm{cm}$. The cathodal zone containing $\gamma$-globulin was cut from the starch gel strip; the fraction separated from normal serum has been referred to as normal $\gamma$-globulin, whereas the fraction separated from the pernicious anemia serum has been referred to as antihuman IF $\gamma$-globulin.

Starch gel segments containing the anodally migrating, bound $\mathrm{Co}^{80} \mathrm{~B}_{12}$ fraction ${ }^{2}$ from saliva or gastric juices were

2 Segments 2 and $3 \mathrm{~cm}$ from the anode were tested initially and were shown to have a similar content of binding material that reacted with antihuman IF $\gamma$-globulin. Thereafter, the segment that contained maximal radioactivity was tested. bisected within an hour of their electrophoretic separation. Each half-segment containing radioactive complex was crushed and mixed with starch gel segments containing normal and antihuman IF $\gamma$-globulin, respectively. The amount of bound $\mathrm{Co}^{80} \mathrm{~B}_{12}$ that was mixed with the $\gamma$-globulin from $0.4-\mathrm{ml}$ of serum did not exceed $10 \mathrm{~m} \mu \mathrm{g}$. These mixtures of crushed gel containing $\gamma$-globulin and bound $\mathrm{Co}^{00} \mathrm{~B}_{12}$ were inserted into starch gel electrophoretic strips and were separated electrophoretically at $\mathrm{pH} 8.6$ for 16 hours at a constant voltage of $5 \mathrm{v}$ per $\mathrm{cm}$. The distribution of radioactivity was again measured by counting $1-\mathrm{cm}$ segments of the gel strips in plastic tubes in a well-type scintillation counter. 
Interaction between bound $\mathrm{Co}^{00} \mathrm{~B}_{12}$ and antihuman IF $\boldsymbol{\gamma}$-globulin was indicated by retention of radioactivity in the application zone (7).

The concentration of $\mathrm{Co}^{60} \mathrm{~B}_{12}$ bound to IF (IF-Co ${ }^{60} \mathrm{~B}_{12}$ ) in individual secretions was calculated from the total content of bound vitamin $B_{12}$ and from the proportion of radioactivity that was retained in the application zone during electrophoresis of the bound $\mathrm{Co}^{60} \mathrm{~B}_{12}$ fraction with antihuman IF $\gamma$-globulin. This measure of IF would be accurate only when IF- $-\mathrm{Co}^{20} \mathrm{~B}_{12}$ in each test mixture was totally combined with antibody, i.e., in the presence of an excess of antihuman IF $\gamma$-globulin. Although it was shown in a previous study that antihuman IF $\gamma$-globulin from $0.4 \mathrm{ml}$ of the pernicious anemia serum would combine with $23.2 \mathrm{~m} \mu \mathrm{g}$ of vitamin $B_{12}$ bound to IF-antibody in $1 \mathrm{ml}$ of this serum combined with $58.0 \mathrm{~m} \mu \mathrm{g} I F-\mathrm{Co}^{\infty 0} \mathrm{~B}_{12}$ [(7), Table I, Patient 1]-further experiments were carried out to prove that when bound $\mathrm{Co}^{80} \mathrm{~B}_{12}$ fractions in amounts that did not exceed $10 \mathrm{~m} \mu \mathrm{g}$ were mixed with antihuman IF $\gamma$-globulin from $0.4-\mathrm{ml}$ of serum, IF- $\mathrm{Co}^{80} \mathrm{~B}_{12}$ in the test fractions was completely combined with antibody. Bound $\mathrm{Co}^{80} \mathrm{~B}_{12}$ fractions separated from normal neutralized gastric juices were added at two concentrations, one (B) twice the other (A), to antihuman IF $\gamma$-globulin from 0.4-ml of serum. The maximal amount of added bound $\mathrm{Co}^{\infty} \mathrm{B}_{12}$ did not exceed $10 \mathrm{~m} \mu \mathrm{g}$. At both concentrations, a similar proportion of each bound $\mathrm{Co}^{80} \mathrm{~B}_{12}$ fraction combined with antibody, indicating that the latter was present in excess. Table $\mathrm{I}$ lists the vitamin $\mathrm{B}_{12}$-binding capacity of eleven, normal, neutralized gastric juices together with the percentage of bound $\mathrm{Co}^{60} \mathrm{~B}_{12}$ that combined with antihuman IF $\gamma$-globulin and the IF- $\mathrm{Co}^{60} \mathrm{~B}_{1:}$ content of each secretion calculated from the former values.

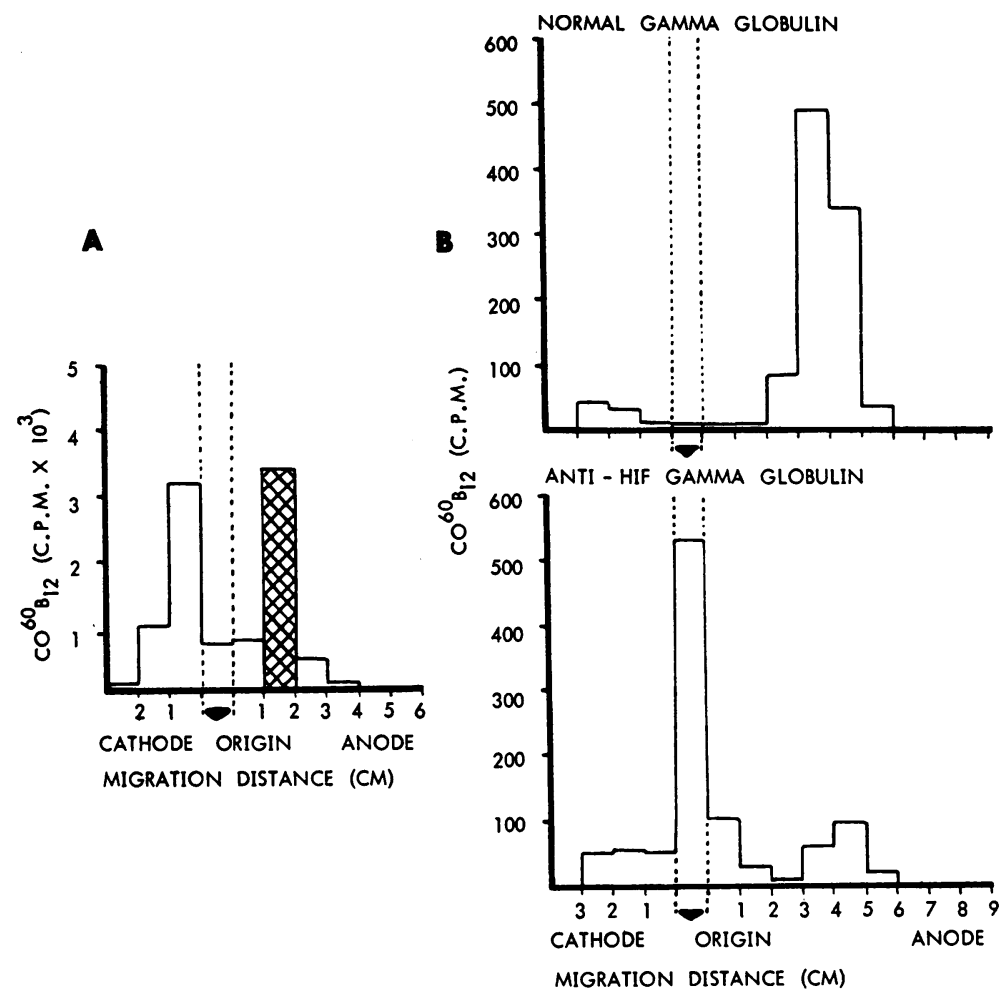

Fig. 2. Starch gel electrophoretic separation of bound $\mathrm{Co}^{\infty} \mathrm{B}_{12}$ in YORMAL GASTRIC JUICE AND ITS INTERACTION WITH NORMAL AND ANTIHUMAN IF $\gamma$-GLOBULIN. A. Starch gel electrophoresis of neutralized gastric juice (from Patient 8, M.E.), containing added $\mathrm{Co}^{60} \mathrm{~B}_{12}, 500 \mathrm{~m} \mu \mathrm{g}$ vitamin $\mathrm{B}_{12}$ per $\mathrm{ml}$ of undiluted secretion. The distribution of cathodally migrating, free $\mathrm{Co}^{00} \mathrm{~B}_{12}$ and anodally migrating, bound $\mathrm{Co}^{20} \mathrm{~B}_{12}$ is plotted. The hatched zone indicates the segment of the electrophoretic strip containing bound $\mathrm{Co}^{60} \mathrm{~B}_{12}$ that was tested for its interaction with normal and antihuman IF $\gamma$-globulin. Electrophoresis was done at $10^{\circ} \mathrm{C}$ for 5 hours at $6 \mathrm{v}$ per $\mathrm{cm}$ and at $\mathrm{pH} 8.6$. B. Bound $\mathrm{Co}^{\infty 0} \mathrm{~B}_{12}$ from electrophoresis $\mathrm{A}$ was divided and mixed with normal and antihuman IF $\gamma$-globulin. Starch gel electrophoresis of these mixtures was carried out at $10^{\circ} \mathrm{C}$ for 16 hours at $5 \mathrm{v}$ per $\mathrm{cm}$ and at $\mathrm{pH} 8.6$. The distribution of radioactivity on the respective electrophoretic strips is plotted. 


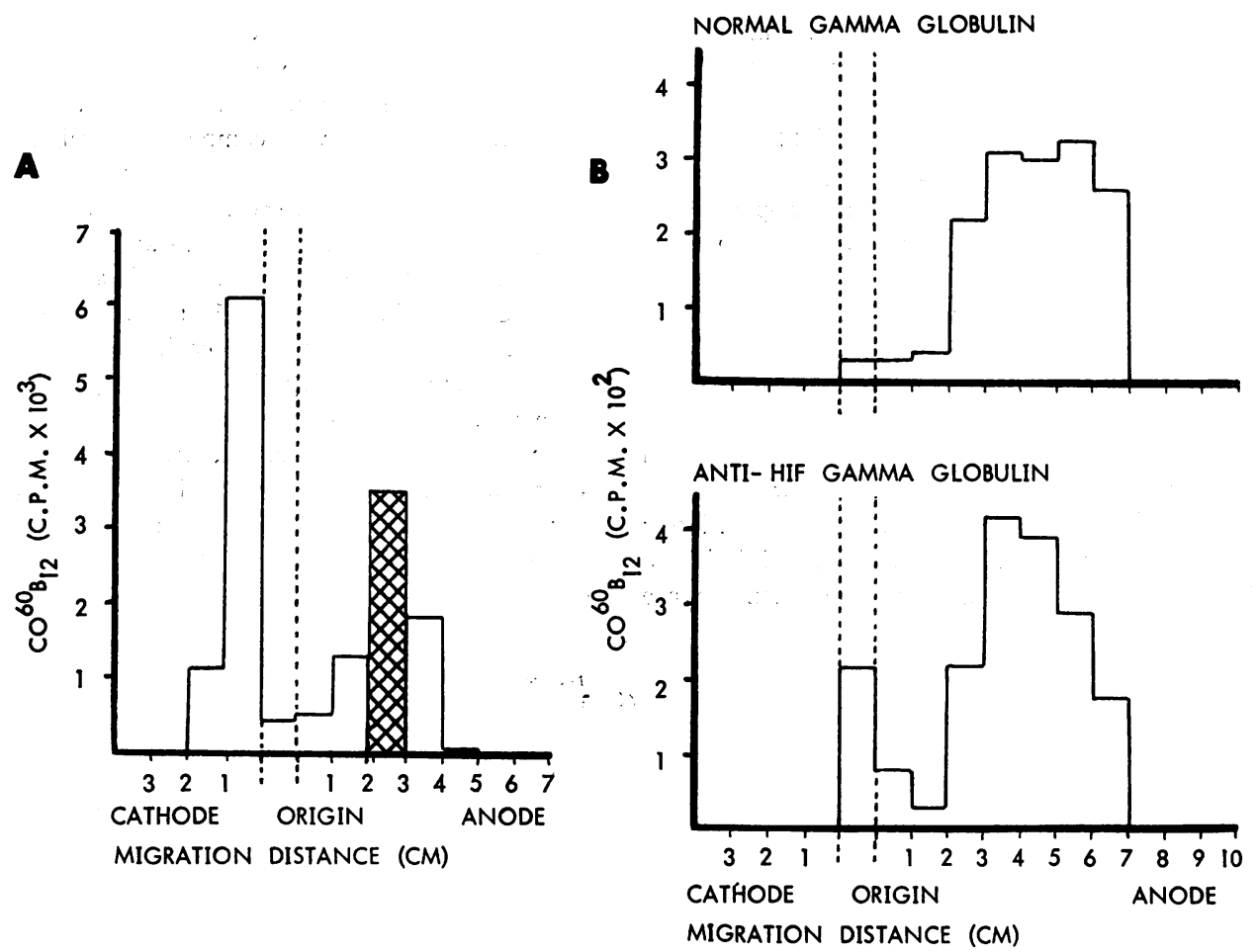

Fig. 3. Bound $\mathrm{Co}^{80} \mathrm{~B}_{12}$ in Gastric JUICE From a PATIENT With atrophic gastritis, but without Pernicious anemia. A. Starch gel electrophoresis of gastric juice from Patient 20, M. W. Concentration of added $\mathrm{Co}^{60} \mathrm{~B}_{12}$ was $515 \mathrm{~m} \mu \mathrm{g}$ per $\mathrm{ml}$ of gastric juice. Electrophoresis was done at $10^{\circ} \mathrm{C}$ for 5 hours at $6 \mathrm{v}$ per $\mathrm{cm}$ and at $\mathrm{pH}$ 8.6. The distribution of $\mathrm{Co}^{\circ 0} \mathrm{~B}_{12}$ is plotted, and the fraction of bound $\mathrm{Co}^{60} \mathrm{~B}_{12}$ that was tested for its interaction with normal and antihuman IF $\gamma$-globulin is indicated by cross-hatching. B. Bound $\mathrm{Co}^{00} \mathrm{~B}_{12}$ from electrophoresis $\mathrm{A}$ was mixed with normal and antihuman IF $\gamma$-globulin. Starch gel electrophoresis of these mixtures was carried out at $10^{\circ} \mathrm{C}$ for 16 hours at $5 \mathrm{v}$ per $\mathrm{cm}$ and at $\mathrm{pH}$ 8.6. The distribution of radioactivity on each electrophoretic strip is plotted.

RESULTS

Electrophoretic separation and quantitation of $\mathrm{Co}^{60} B_{12}$-binding substances in saliva and gastric juices. When saliva, achlorhydric gastric juice, or normal, neutralized gastric juice mixed with $\mathrm{Co}^{60} \mathrm{~B}_{12}$ was subjected to starch gel electrophoresis, bound $\mathrm{Co}^{60} \mathrm{~B}_{12}$ migrated anodally and was separated from unbound (free) $\mathrm{Co}^{60} \mathrm{~B}_{12}$. $\quad \mathrm{Co}^{60} \mathrm{~B}_{12}$ complexes from saliva, achlorhydric gastric juice, and normal, neutralized gastric juice exhibited slight differences in anodal electrophoretic mobility (Figures 2-5).

The quantity of vitamin $\mathrm{B}_{12}$-binding substances in different secretions, calculated from the concentration of added vitamin $\mathrm{B}_{12}$ and from the proportion of anodally migrating radioactivity, is expressed in Table II and Figure 1, A columns. It is apparent from these data that the total binding capacity of gastric juices did not distinguish patients with pernicious anemia from those with normal gastric secretion, or from those with achlorhydria and normal vitamin $\mathrm{B}_{12}$ absorption.

Electrophoresis of bound $C^{66} B_{12}$ fractions from saliva and gastric juices with normal and antihuman IF $\gamma$-globulin. The patterns of electrophoretic migration of bound $\mathrm{Co}^{60} \mathrm{~B}_{12}$ complexes mixed with normal and antihuman IF $\gamma$-globulin are shown in Figures $2 \mathrm{~B}$ through $5 \mathrm{~B}$. Bound $\mathrm{Co}^{60} \mathrm{~B}_{12}$ prepared from normal, neutralized gastric juice showed an altered electrophoretic mobility in the presence of antihuman IF $\gamma$-globulin (Figure 2B). Radioactivity was retained in the application zone. indicating that $\mathrm{IF}-\mathrm{Co}^{60} \mathrm{~B}_{12}$ was combining with antibody (7). In the presence of normal $\gamma$-globulin, the bound $\mathrm{Co}^{60} \mathrm{~B}_{12}$ fraction migrated anodally as a single radioactive zone (Figure 2B). Bound 
$\mathrm{Co}^{60} \mathrm{~B}_{12}$ separated from the gastric juice of patients with histamine-fast achlorhydria and normal vitamin $\mathrm{B}_{12}$ absorption combined in part with antihuman IF $\gamma$-globulin, but also contained a high proportion of unreactive, anodally migrating bound $\mathrm{Co}^{60} \mathrm{~B}_{12}$ (Figure 3 and Table II).

Complexes from the gastric juice of pernicious anemia patients and from saliva did not react with antihuman IF $\gamma$-globulin. In the presence of both normal and antihuman IF $\gamma$-globulins, these radioactive complexes retained their anodal electrophoretic mobility (Figures 4 and 5).

The concentration IF-Co ${ }^{60} \mathrm{~B}_{12}$ in individual secretions was calculated from the total content of bound vitamin $\mathrm{B}_{12}$ and from the proportion of radioactivity that was retained in the zone of application during electrophoresis with antihuman IF $\gamma$-globulin. These values are listed in Tables $\mathrm{I}$ and II and in Figure 1, B columns. An excess of antibody (antihuman IF $\gamma$-globulin) ensured that all antigen $\left(\mathrm{IF}-\mathrm{Co}^{60} \mathrm{~B}_{12}\right)$ present in the tested secretions was measured. The difference between the total vitamin $\mathrm{B}_{12}$-binding capacity of each secretion and its IF- $\mathrm{Co}^{60} \mathrm{~B}_{12}$ content is a measure of the content of non-IF-binding substances.

\section{DISCUSSION}

The measurement of the vitamin $\mathrm{B}_{12}$-binding capacity of secretions depends on the partition of added vitamin $\mathrm{B}_{12}$ into bound and unbound fractions. In the experiments described, this separation was achieved by starch gel electrophoresis of native secretions without preliminary storage, concentration, or dialysis. This method had several advantages over the dialysis and paper electrophoretic techniques described by other workers $(1,2)$. A decrease in binding capacity, due either to denaturation of labile IF, or to dissociation of
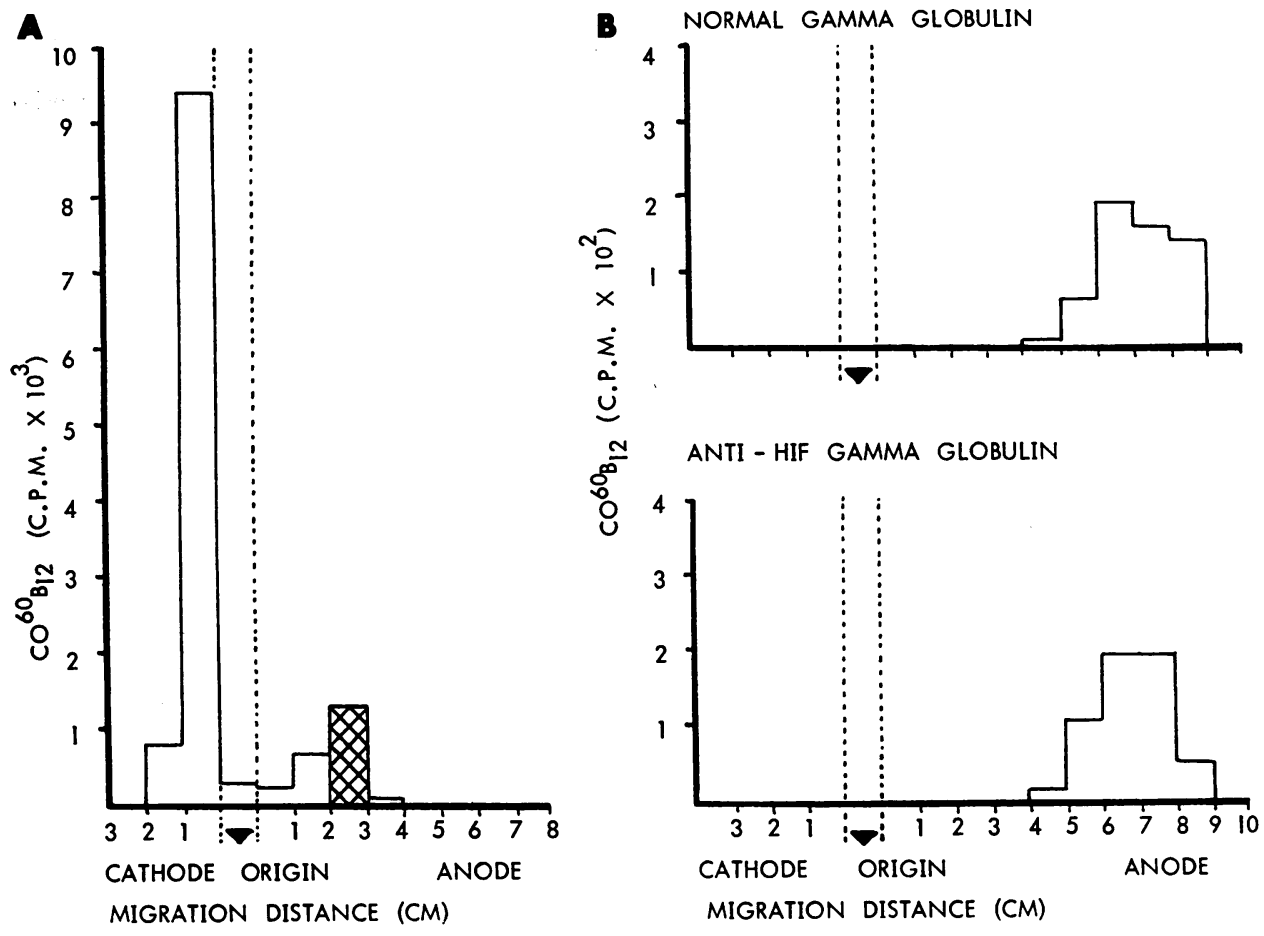

Fig. 4. Bound $\mathrm{Co}^{60} \mathrm{~B}_{12}$ in Gastric JUICE from a patient with perniciols anemia. A. Starch gel electrophoresis of gastric juice from Patient 22, M.W. The concentration of added $\mathrm{Co}^{80} \mathrm{~B}_{12}$ was $515 \mathrm{~m} \mu \mathrm{g}$ per $\mathrm{ml}$ of gastric juice. Electrophoresis was done at $10^{\circ} \mathrm{C}$ for 5 hours at 6 $\mathrm{v}$ per $\mathrm{cm}$ and at $\mathrm{pH}$ 8.6. The distribution of $\mathrm{Co}^{60} \mathrm{~B}_{12}$ is plotted, and the fraction of bound $\mathrm{Co}^{60} \mathrm{~B}_{12}$ that was tested for its interaction with normal and antihuman IF $\gamma$-globulin is indicated by crosshatching. B. Bound $\mathrm{Co}^{80} \mathrm{~B}_{12}$ from electrophoresis $\mathrm{A}$ was mixed with normal and antihuman IF gamma globulin. Starch gel electrophoresis of these mixtures was carried out at $10^{\circ} \mathrm{C}$ for 16 hours at $5 \mathrm{v}$ per $\mathrm{cm}$ and at $\mathrm{pH}$ 8.6. The distribution of radioactivity on each electrophoretic strip is plotted. 

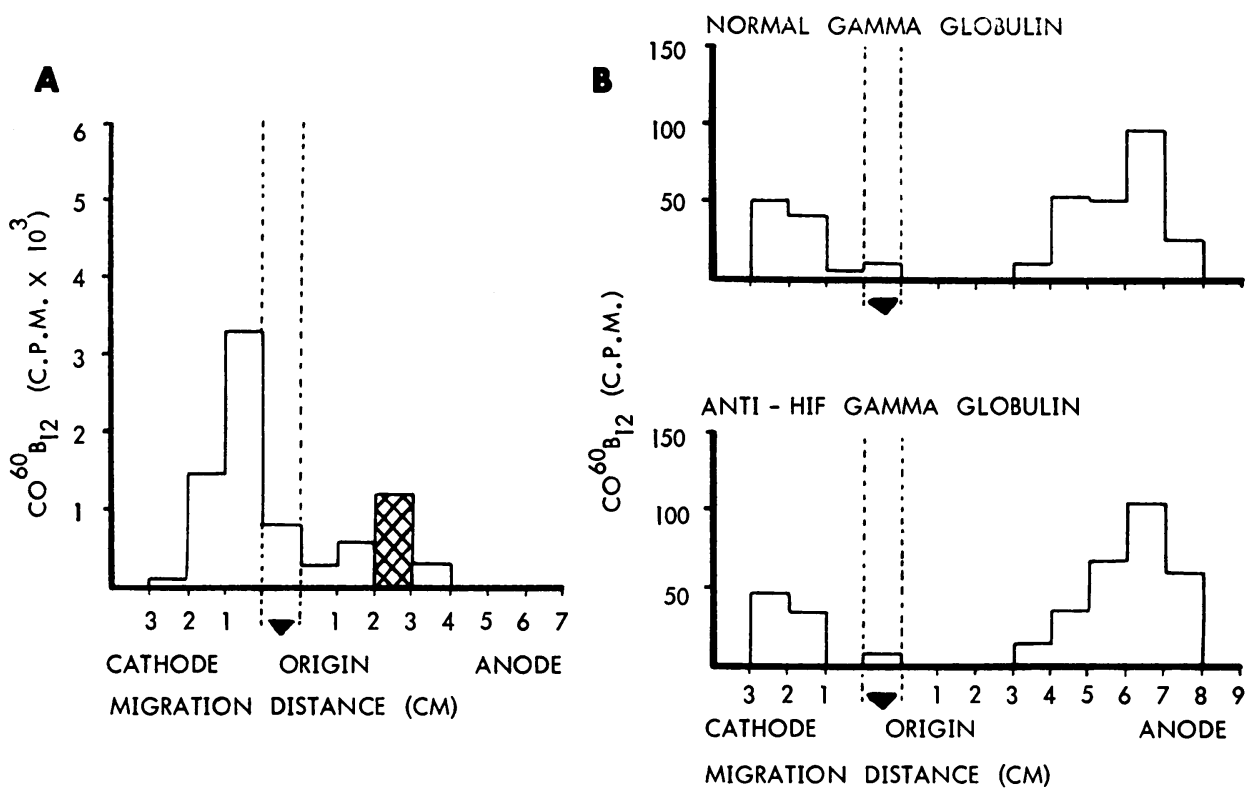

Fig. 5. Bound $\mathrm{Co}^{60} \mathrm{~B}_{12}$ in saliva. A. Starch gel electrophoresis of saliva from Patient 5, J.S. The concentration of added $\mathrm{Co}^{60} \mathrm{~B}_{12}$ was $265 \mathrm{~m} \mu \mathrm{g}$ per $\mathrm{ml}$ of saliva. Electrophoresis was done at $10^{\circ} \mathrm{C}$ for 5 hours at $6 \mathrm{v}$ per $\mathrm{cm}$ and at $\mathrm{pH}$ 8.6. The distribution of $\mathrm{Co}^{80} \mathrm{~B}_{12}$ is plotted, and the fraction of bound $\mathrm{Co}^{80} \mathrm{~B}_{12}$ that was tested for its interaction with normal and antihuman IF $\gamma$-globulin is indicated by cross-hatching. B. Bound $\mathrm{Co}^{60} \mathrm{~B}_{12}$ from electrophoresis A was mixed with normal and antihuman IF $\gamma$-globulin. Starch gel electrophoresis of these mixtures was carried out at $10^{\circ} \mathrm{C}$ for 16 hours at $5 \mathrm{v}$ per $\mathrm{cm}$ and at $\mathrm{pH}$ 8.6. The distribution of radioactivity on each electrophoretic strip is plotted.

bound $\mathrm{Co}^{60} \mathrm{~B}_{12}$ during exhaustive dialysis, was avoided; furthermore, the binding fractions prepared by starch gel electrophoresis were available for subsequent study.

Neither the total vitamin $\mathrm{B}_{12}$-binding capacity of secretions, nor the electrophoretic mobility of their bound $\mathrm{Co}^{60} \mathrm{~B}_{12}$ components indicated the presence of IF. Although the average vitamin $\mathrm{B}_{12^{-}}$ binding capacity of acid secretions exceeded that of saliva or achlorhydric secretions (Figure 1), there was a wide range of values in each group, with considerable overlap. Similarly, although the electrophoretic mobility of bound $\mathrm{Co}^{60} \mathrm{~B}_{12}$ in saliva and in gastric juice from patients with pernicious anemia exceeded that of bound $\mathrm{Co}^{60} \mathrm{~B}_{12}$ in normal, neutralized gastric juice (Figures 2, 4, 5), this difference in electrophoretic mobility was not great enough to result in the separation of IF from other vitamin $B_{12}$-binders present in individual achlorhydric gastric juices of patients with normal vitamin $B_{12}$ absorption (Figure 3 ).

Bound $\mathrm{Co}^{60} \mathrm{~B}_{12}$ separated from gastric juices that contained IF-as indicated by their acidity, or by normal Schilling tests in patients with atrophic gastritis-combined with antihuman IF $\gamma$-globulin. Bound $\mathrm{Co}^{60} \mathrm{~B}_{12}$ fractions separated from the gastric juice of patients with pernicious anemia and from saliva were unreactive. These results establish that IF may be identified not only by its ability to potentiate vitamin $\mathrm{B}_{12}$ absorption, but also by its specific reaction with antihuman IF $\gamma$-globulin. This forms the basis of an in vitro test for IF and of a method for measuring the IF content of secretions.

A significant finding in this study was the relatively large amount of vitamin $\mathrm{B}_{12}$-binding substance in normal, neutralized gastric juice that did not combine with antihuman IF $\gamma$-globulin. Although the IF activity of this fraction has not been tested in vivo, it is probable that this is a biologically inactive (non-IF), vitamin $\mathrm{B}_{12}$-binding substance or substances.

Recently, Sullivan, Herbert, and Castle used a mucosal homogenate from guinea-pig ileum to identify IF in vitro (11). These workers showed that gastric juice with IF activity, as indicated by 
vitamin $\mathrm{B}_{12}$ absorption tests, potentiated the uptake of $\mathrm{Co}^{60} \mathrm{~B}_{12}$ by the mucosal preparation. Gastric juice from pernicious anemia patients with complete vitamin $\mathrm{B}_{12}$ malabsorption was inactive. In the future, the use of these in vitro techniques may be important in developing our understanding of IF physiology.

\section{SUMMARY}

1. The vitamin $B_{12}$-binding capacity of saliva and gastric secretions was measured by the partition of added cobalt ${ }^{60}$-labeled vitamin $\mathrm{B}_{12}\left(\mathrm{Co}^{60}\right.$ $\mathrm{B}_{12}$ ) into bound and unbound (free) fractions during starch gel electrophoresis.

2. The presence of intrinsic factor in secretions could not be established either on the basis of their total vitamin $\mathrm{B}_{12}$-binding capacity, or on the electrophoretic mobility of their bound $\mathrm{Co}^{60} \mathrm{~B}_{1}$. components.

3 . The interaction of normal and antihuman intrinsic factor gamma globulin with bound $\mathrm{Co}^{60} \mathrm{~B}_{12}$ fractions from saliva and gastric juices was studied by electrophoresis. Bound $\mathrm{Co}^{60} \mathrm{~B}_{12}$ separated from gastric juices that contained intrinsic factor-as indicated by their acidity, or by normal Schilling tests in those patients with atrophic gastritis-combined with antihuman intrinsic factor $\gamma$-globulin, whereas bound $\mathrm{Co}^{60} \mathrm{~B}_{12}$ fractions from other secretions were unreactive.

4. These studies demonstrate, therefore, that intrinsic factor can be identified not only by in vivo vitamin $\mathrm{B}_{12}$ absorption tests, but also by its specific reaction in vitro with antihuman intrinsic factor $\gamma$-globulin. Thus, an in vitro test for intrinsic factor and a method of measuring specific intrinsic factor binding of vitamin $\mathrm{B}_{12}$ are established.

\section{ACKNOWLEDGMENT}

The authors wish to thank Dr. David V. Becker for the use of radioisotope equipment.

\section{ADDENDUM}

After this manuscript was submitted for publication, studies were carried out by Reisner, Wolff, McKay, and
Doyle (12) on two patients (Cases 1 and 2) with previously established, juvenile pernicious anemia. Their fasting and stimulated gastric juices were of normal acidity, $\mathrm{pH} 1$ to 2 . The vitamin $\mathrm{B}_{12}$-binding substances present in the stimulated secretions in concentration of 118 and $124 \mathrm{~m} \mu \mathrm{g}$ vitamin $\mathrm{B}_{12}$ per $\mathrm{ml}$, respectively, did not react with intrinsic factor antibody. Thus, the absence of intrinsic factor in these acid secretions was confirmed.

\section{REFERENCES}

1. Gräsbeck, R. Studies on the vitamin $B_{1:}$ binding principle and other biocolloids of human gastric juice. Acta med. scand. 1956, 154, suppl. 314, 1.

2. Glass, G. B. J., H. Uchino, and G. Schwartz. Study of vitamin $B_{12}$ binders in gastric juice of pernicious anemia patients and individuals with atrophic gastritis and histamine-fast anacidity. Proc. 8th int. Congr. Hemat. (Tokyo) 1960, p. 262.

3. Gullberg, R. Electrophoretic fractionation of $B_{1:-}$ binders in gastric juice from patients with pernicious anemia and from controls. Proc. Soc. exp. Biol. (N. Y.) 1960, 105, 62.

4. Bertcher, R. W., L. M. Meyer, and I. F. Miller. $\mathrm{Co}^{\infty}$ vitamin $\mathrm{B}_{12}$ binding capacity of normal human saliva. Proc. Soc. exp. Biol. (N. Y.) 1958, 99, 513.

5. Taylor, K. B. Inhibition of intrinsic factor by pernicious anæmia sera. Lancet 1959, 2, 106.

6. Schwartz, M. Intrinsic factor antibody in serum from patients with pernicious anemia. Lancet 1960. 2, 1263 .

7. Jeffries, G. H., D. W. Hoskins, and M. H. Sleisenger. Antibody to intrinsic factor in serum from patients with pernicious anemia. J. clin. Invest. 1962, 41, 1106.

8. Kay, A. W. Effects of large doses of histamine on gastric secretion of $\mathrm{HCl}$ : an augmented histamine test. Brit. med. J. 1953, $2,77$.

9. Schilling, R. F. Intrinsic factor studies. II. The effect of gastric juice on the urinary excretion of radioactivity after the oral administration of radioactive vitamin $B_{12}$. J. Lab. clin. Med. 1953, 42, 860.

10. Jeffries, G. H., F. W. Smith, D. W. Hoskins, and M. H. Sleisenger. Fractionation of the nondialyzable components of normal human gastric juice by starch gel electrophoresis. Gastroenterology 1961, $41,467$.

11. Sullivan, L. W., V. Herbert, and W. B. Castle. In vitro assay for human intrinsic factor. Clin. Res. 1962, 10, 208.

12. Reisner, E. H., J. A. Wolff, R. J. McKay, Jr., and E. F. Doyle. Juvenile pernicious anemia. Pediatrics $1951,8,88$. 